Pazouki K, Forbes N, Norman RA, Woodward MD.

Investigation on the impact of human-automation interaction in maritime operations.

Ocean Engineering 2018, 153, 297-304.

\section{Copyright:}

(C) 2018. This manuscript version is made available under the CC-BY-NC-ND 4.0 license

DOI link to article:

https://doi.org/10.1016/i.oceaneng.2018.01.103

Date deposited:

$26 / 01 / 2018$

Embargo release date:

20 February 2019

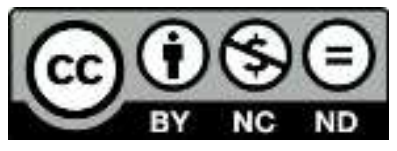

This work is licensed under a

Creative Commons Attribution-NonCommercial-NoDerivatives 4.0 International licence 


\title{
Investigation on the impact of human-automation interaction in maritime operations
}

\author{
Kayvan Pazouki ${ }^{\mathrm{a}^{*}}$, Neil Forbes ${ }^{\mathrm{a}}$, Rosemary A. Norman ${ }^{\mathrm{a}}$, Michael .D. Woodward ${ }^{\mathrm{b}}$ \\ a School of Marine Science and Technology, Armstrong Building, Queen Victoria Road, Newcastle \\ upon Tyne, NE1 7RU, United Kingdom. \\ ${ }^{b}$ National Centre for Maritime Engineering and Hydrodynamics, Australian Maritime College, \\ University of Tasmania, Swanson Building, Launceston TAS 7250, Locked Bag 1399. \\ E-mail: michael.woodward@utas.edu.au \\ *Corresponding Author, School of Marine Science and Technology, Armstrong Building, Queen \\ Victoria Road, Newcastle upon Tyne, NE1 7RU, United Kingdom. Telephone: +44(0)191 2085865. \\ E-mail: kayvan.pazouki@ncl.ac.uk
}

\begin{abstract}
The level of automation around the world has grown significantly over the past few decades, and continues to do so. There are many reasons behind this trend, such as safety and potential economic benefits. However, when automation fails or behaves unexpectedly, the impact on the human operator can be severe. In a safety critical operation, such as on the bridge of a ship, the consequences could be catastrophic.
\end{abstract}

The research presented in this paper aims to improve understanding in this important area of study for the maritime industry. An experiment was conducted to assess the awareness of deck officer cadets in the recognition of a developing emergency situation due to failure of the autopilot. Using the results from this experiment and experiences from the aviation industry, the paper provides a potential strategy to improve automation monitoring and accuracy of situation awareness. This has led to the identification of opportunities to improve human-machine interaction.

\section{Keywords}




\section{Nomenclature}

CAA

Civil Aviation Authority

SA

Situation Awareness

\section{Introduction}

In safety critical industries the level of computerisation and automation has increased over the past few decades (Hadnett, 2008). In this context, automation has been introduced with the intention of increasing safety, efficiency, and productivity, and hence reducing operating costs (Harris, 2011). Commercial aviation was one of the leaders in this trend, with operations becoming increasingly automated in the 1980s (Sarter, 2008). Whilst this has been a mostly successful initiative, with automation handling routine operations well (Onnasch et al., 2014), automation has inadvertently created new accident pathways (Lützhöft and Dekker, 2002).

Automation limitations are commonly cited as issues such as degraded manual skills, ineffective monitoring, inaccurate situation awareness and over-reliance (Dhami and Grabowski, 2011). Recent aircraft accidents related to these issues are a cause of great concern in the aviation industry (FAA, 2013).

Maritime operations lag behind aviation in terms of technology introduction on the bridge (Schager, 2007), and so there may be scope to leverage experience from aviation to reduce the likelihood of similar occurrences in shipping. Alongside technology changes, the demographics of the deck officer population are also evolving. Over the next 15 to 20 years, a significant number of masters and officers will be reaching the age of retirement (Department for Transport, 2014), to be replaced with crews who have only ever experienced heavily automated operations. Therefore, the trends associated with the negative impacts of automation could become even worse.

Research into the area of automation, and the interaction between human and machine, is relevant to current issues and future threats. This paper aims to improve understanding of automation limitations, as well as identifying current industry trends and ways to improve the human-automation partnership. 


\subsection{Automation Technology}

Automation has been defined as the mechanical or electrical accomplishment of work and in many cases it "involves the substitution of automation components for tasks that humans are capable of performing" (Wickens and Hollands, 2000). The levels of automation are typically split between (Balfe et al., 2015): information acquisition, information analysis, decision and action selection, and action implementation. With the introduction of computerised systems, operators have become increasingly supervisory in their role (Meister, 1999), interacting with systems through manual and automatic control (Lee and Moray, 1994) and for this reason human-computer interaction became a topic of significant research interest in the $1980 \mathrm{~s}$ (Guastello, 2006).

Automation may be employed for a number of reasons, such as reducing workload, making up for human performance limitations, due to the operating environment being unsuitable for a human and/or reducing costs (Wickens and Hollands, 2000). Wiener and Curry (1980) and Balfe et al. (2015) considered increased capacity and productivity, reduced manual workload and fatigue, economical utilisation of machines, more precise handling of routine operations and reduced individual skills differences as benefits of automation.

However, these benefits are dependent on an automated system being of good design, and the operator receiving sufficient training in the effective use of the system (Parasuraman and Manzey, 2010). Despite the benefits, Wiener and Curry (1980) suggested that automation has limitations, which will contribute to accidents. These limitations are over-reliance and complacency, low alertness, low proficiency in manual skills, automation bias and automation induced failures. Bainbridge (1983) also discussed in "The ironies of automation" areas of manual control skills, cognitive skills and monitoring. Bainbridge mentioned that when automation was introduced, the operator was originally tasked to perform manual control, left to monitor the automation, and intervene when failure occurred. However, the net result led to deterioration of manual skills due to lack of practice. Although monitoring seems to be a straightforward task, most of the time the process or system works smoothly and there is very little to do. Therefore, the operator can find it difficult to maintain effective monitoring for more than half an hour, when information is largely unchanged (Bainbridge, 1983). Whilst automation can outperform human operators at routine tasks, when automation fails the effect on human performance can be catastrophic (Onnasch et al., 2014). 


\subsection{Review of accident caused by automation technology}

Whilst intended to reduce human error, automation systems may result in larger errors (Wiener, 1989) and as a result new accident sequences have been inadvertently created through automation implementation (Lützhöft and Dekker, 2002).

Automation and its effects on the human operator in aviation has been studied for decades (Carr, 2015). According to the UK Civil Aviation Authority's (CAA) 'Global Fatal Accident Review 2002 - 2011' (CAP 1036), of the 205 accidents over that period, $62 \%$ had flight crew related factors as the primary cause, which could be related to degraded manual handling skills (CAA, 2013).

The problems associated with ineffective monitoring and degraded situation awareness were identified by Wiener and Curry (1980) and this issue continued to be a concern in the 1990s (FAA, 1990; Parasuraman and Riley, 1997). Into the 2000s, the common theme of over-reliance on the automation, in spite of the guidance issued, still remains. The 2002-2011 accident data from the CAA indicates that effective automation monitoring remains a key concern for the aviation industry today. Combining ineffective monitoring, with over-reliance on automation and consequently degraded situation awareness, can lead to a startled response when faced with sudden automation failure (Jarvis et al., 2014). This in turn can lead to poor performance from the crew, and the loss of the aircraft.

Similar situations could happen in the shipping industry and it is worthwhile to learn lessons from the aviation industry. A ship's navigating bridge could be considered equivalent to the aeroplane cockpit. A ship's bridge has positions for navigation, traffic surveillance and manoeuvring, route planning, communications and safety operations, manual steering, and docking operations (Linna, 2005). On modern vessels, separate pieces of equipment, such as a Global Positioning System (GPS), electronic charts and depth sounders, are integrated into one main system (Belev, 2004). An integrated system must decide what information to display, and in some cases, what actions to take based on that information (Mills, 2006). A typical integrated bridge system is shown in Figure 1. 


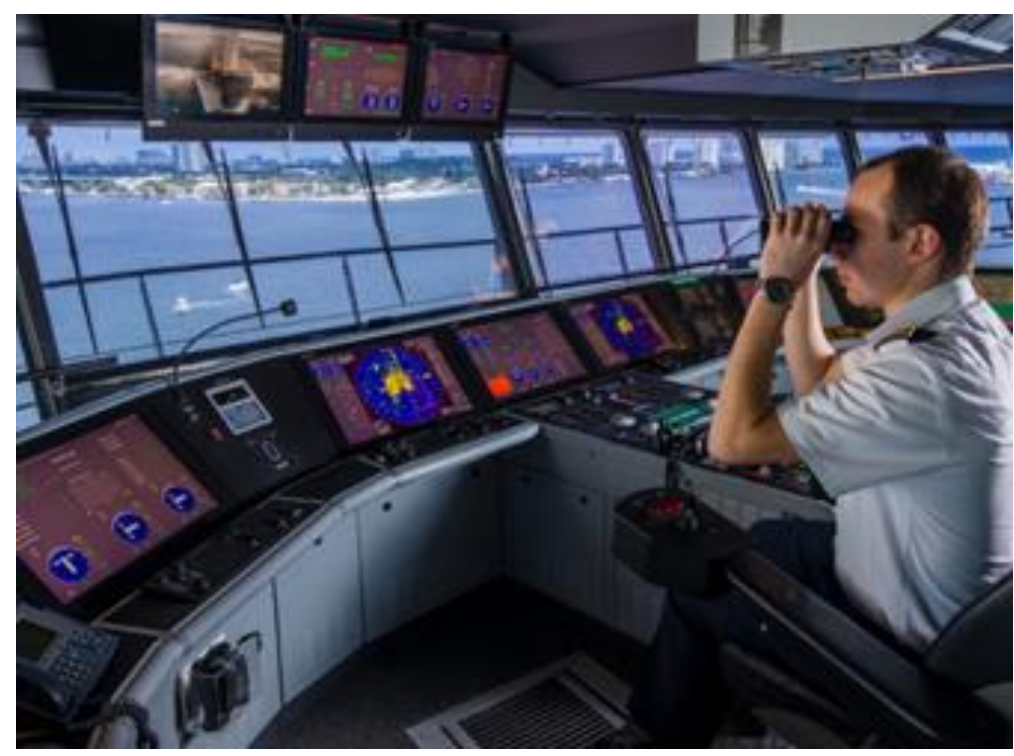

Figure 1: A typical integrated bridge system (Sperry Marine, 2014)

However, the increased levels of technology and automation on the bridge have not been trouble free (Mills, 2006) (Schager, 2007). Hadnett (2008) states:

"The relentless drive within the shipping community to introduce electronic navigation aids to merchant ships had the principal stated objective of improving safety by enhancing situational awareness. However, some of the doubts expressed at the inception of these initiatives regarding their likely success have been realised, in that there is now a commonly held view that the general standard of bridge watch-keeping has been eroded, leading to several collisions and groundings."

In light of accidents due to automation failure, the Short Course Programme in Automated System in Shipping (SURPAS), an EU funded project, provided specialist training to seafarers to understand the automation systems and enable them to comprehend the weaknesses and limitations of such systems. In the initial stage of the project, in reviewing sea accident investigations, it was found that $60 \%$ of shipping accidents are due to human error. In this study it was concluded that better education and training is one of the solutions to potentially reduce such accidents. They also proposed cooperation between users and producers of automated systems to create a platform for transfer of knowledge and ultimately eliminate manmachine interface problem (SURPASS, 2012).

\subsection{Human Factors related to accidents}

Human Factors, as a research topic, is a "multifaceted subject drawing on psychology, sociology, physiology and medicine, engineering and management science" (Harris, 2011). As 80\% of accidents in high risk 
industries can be attributed to human error (O'Connor et al., 2008), there is a clear benefit to understanding the human-machine interaction.

Both technical and human action barriers are built into a well-designed system, with a view to improving resilience. This is in order to protect both humans and machines from each other's weaknesses ( $\mathrm{Re}$ and Macchi, 2010). Human and machine related errors need to line up to create a pathway for an accident sequence to propagate and pass through what should have been barriers. Human factors in relation to the automation technology that contribute to the occurrence of an accident are human error, lack of situation awareness, automation complacency and automation bias.

\subsubsection{Human Error}

Consistent definitions of human error are summarised by (Wickens and Hollands, 2000), who suggest that error can occur if the operator interprets the situation incorrectly, the action decided upon is incorrect, or the action decided upon may not be carried out correctly. The performance of a particular individual, and so the likelihood of error, can be influenced by many factors such as skill, experience, age, fatigue, humidity and noise (Park, 2011). Hetherington et al. (2006) reviewed the literature on safety in shipping and addressed human error failures at design, personnel and organisational levels. In their review, they highlighted the most common human error factors were due to misjudgement and improper lookout or watch keeping. In another related study, Turan et al. (2016) presented the outcome of the SEAHORSE project focused on safety in marine transport and addressed human and organisational factors. In their analytical study, they found over $50 \%$ of underlying accidents were attributed to human error out of which the majority was due to inattention followed by inadequate communication and situation awareness.

With the exception of intentional violation, people do not set out to cause injury, death or damage as a result of their error. After all, an operator's own life may be at risk as the scenario plays out. With the benefit of hindsight, it can be all too easy to criticise the incorrect actions performed by the human operator (Perrow, 1984). Therefore, the emphasis of human error study should not be on blame, but on understanding why the error has occurred and asking "why did this action or assessment make sense to people at that time and place?” (Lützhöft and Dekker, 2002). However, in the SAFETY II approach, it is suggested to look for what goes right as well as what goes wrong. It also suggests that "the purpose of investigation is to understand 
how tings usually go right as a basis for explaining how things occasionally go wrong" (Hollnagel, E et al. 2013). With this mind-set, the opportunity exists to learn and so to implement changes to prevent reoccurrence.

\subsubsection{Situation Awareness}

Situation awareness may be defined as the need to understand the current state and project the future state of a system (Sneddon et al., 2013) in order to maintain safe operations. Accurate situation awareness is critical in the operator's decision making process (Craig, 2012) and requires the dynamics of the situation and the external environment to be understood (Wickens and Hollands, 2000). Situation awareness requires an accurate mental model, which is defined as a person's understanding of how a system functions and how its current state may develop based on the known parameters (Endsley, 2012). If a highly complex system is not perfectly reliable, an operator's situation awareness can be degraded (Onnasch, 2015). Once situation awareness is degraded, operators are slower to detect problems and require time to re-orientate themselves with the situation and the system (Endsley, 1995).

\subsubsection{Automation Complacency}

Humans can become complacent with any task and environment, from a simple manual routine to the use of automated bridge equipment (Squire, 2009). Operators of highly automated systems may perceive themselves to be in a supervisory role ((Onnasch, 2015). In time, the operator starts to assume that the system is infallible, and so will no longer actively monitor what is happening, meaning they have become complacent (Mosier et al., 2013). Automation complacency reduces effectiveness in monitoring as the operator assumes that the system is reliable and therefore failure detection deteriorates. In another study on effectiveness of automation monitoring by Parasuraman and Manzey (2010) it was concluded that operators of constantly high reliability systems were $50 \%$ less likely to detect failures, than operators of unreliable systems. However, it is worthwhile to mention that complacency only becomes a problem when automation fails (Wickens and Hollands, 2000).

\subsubsection{Automation Bias}


Automation bias is a term applied when humans perceives automation "as powerful agents with superior analysis capability" (Lee and See, 2004). Operators can trust the automated system so much that they ignore other sources of information, including their own senses (Carr, 2015). Automation bias can be particularly powerful when the operator experiences confirmation bias. This is when humans seek information that confirms their current understanding of a situation, ignoring any evidence against the held belief. When faced with supposedly exact information from an electronic source, humans can disregard their own senses (Schager, 2007). Therefore, if the automation agrees with the held belief of the situation, then any other information will likely be ignored, resulting in poor decision making (Parasuraman and Manzey, 2010). Operators are particularly at risk from the bias effect at times of high stress (Sneddon et al., 2013), when task saturation occurs and performance is already low.

\section{Materials and Methods}

The maritime industry has realised, despite increased safety standards and technological improvements including automation, accidents still occur. Some EU funded projects (SEAHORSE, 2016 and SURPASS, 2012) and research reviewed the literature in shipping accidents and highlighted that the failure in automation may bring serious causalities. In this paper, the authors conduct a pilot study monitoring the performance of 12 deck officer cadets using simulation video and endeavouring to understand the attitudes (e.g. level of trust in automation) of future seagoing deck officers towards shipboard automation. In the selection process for the test subjects, the aim was to have people with similar seagoing experience, but as far as possible from different age groups, so that the effect of specific training could be highlighted in the results of this pilot study. It should be noted that the number of available participants meeting this requirement was relatively small.

\subsection{Automation Monitoring Experimental Setup}

An experiment was planned and carried out to assess whether highly reliable automation in the shipping industry can lead to ineffective monitoring and inaccurate situation awareness by the operator, as well as to trial a strategy to improve operator monitoring effectiveness. During the initial stage of the research an experiment was designed and necessary materials were developed. The material prepared for the experiment 
included series of recorded simulation videos, briefing video, paper charts, questionnaire and data recording sheet. A pilot study was then conducted and the resulting data collected for analysis.

A large container vessel was chosen as the case ship for this experiment, consisting of an interactive bridge watch simulation. A series of scenarios were set in the developed simulation and two major faults were introduced: "Possible traffic conflict" and "Deviation from course". Initially, in order to build trust in the test subjects, the bridge watch simulation system functioned as it should, as if automation correctly controlled the situation. In the second scenario, a traffic hazard situation was defined in the simulation, which eventually would have triggered an alarm to alert the test subject. In the final scenario, a subtle autopilot failure occurred and the vessel made a gradual, unexpected turn without an alarm to notify the test subject. The test measured how quickly the failure was noticed (i.e. recognition time), and accuracy of situation awareness. Table 1 shows the scenarios.

Table 1: Automation monitoring experiment scenarios.

\begin{tabular}{lll}
\hline Video & Simulation Change & Alarm Triggered \\
\hline $\mathbf{1}$ & Briefing & \\
\hline $\mathbf{2}$ & None & None \\
\hline $\mathbf{3}$ & Possible traffic conflict & Traffic alert \\
\hline $\mathbf{4}$ & Deviation from course & None \\
\hline
\end{tabular}

The simulations were recorded with a VSTEP Ship Simulator 2008 (VSTEP, 2008), and a voiceover was recorded to give a set of packaged videos. Test subjects had sufficient opportunities to identify changes visually such as clouds in the sky, vessel position relative to the coastline, and heel motion. Figure 2 shows a screenshot of a typical video in the set of scenarios. 


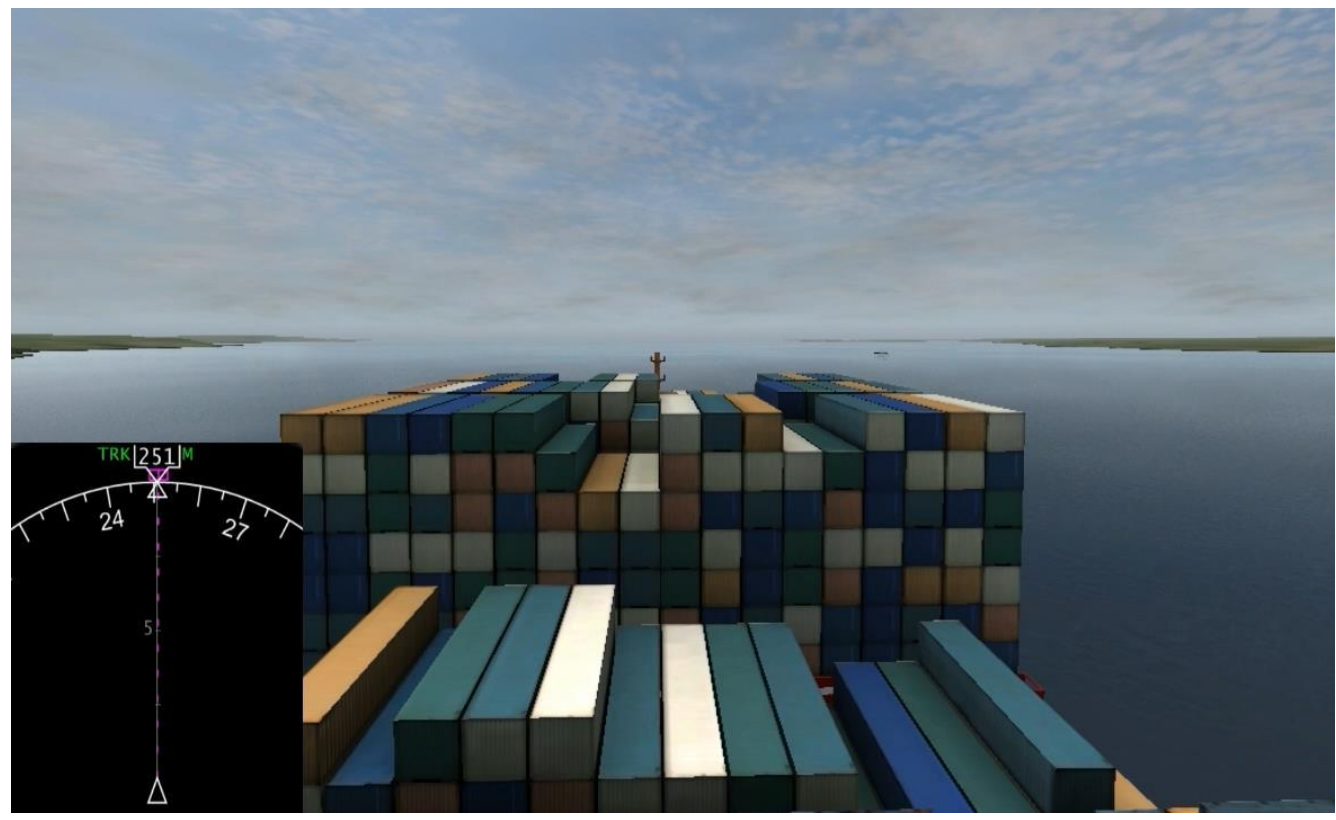

Figure 2: A screenshot of a video from experiment

Each simulation scenario was planned to run for 5 minutes and the test subject could show their concern, indicating their navigational awareness, by an alarm or show of hand followed by noting down what they have noticed. In the final scenario, deviation from course commenced after 2 minutes until the end of the simulation. Test subjects were expected to notice the change in course anytime within the 3 minutes. By the end of the simulation, if any test subject didn't notice the deviation, it would be considered as failure to recognise.

To recreate workload on the bridge, a set of questions was created, for completion during the experiment. Nested within the questionnaire were questions containing background information, training received and that would indicate current attitude towards automation, such as level of trust and automation complacency. The level of automation trust amongst the experiment participants was scored on a scale of 1 to 5 , where for the strength of agreement, 1 is 'Strongly Disagree', 3 is 'Neither Agree or Disagree' and 5 is 'Strongly Agree.

\subsection{Experiment Procedure}

The automation monitoring experiment was conducted with deck officer cadets from a local maritime school. All of test subjects (deck officer cadets) who were selected had similar seagoing experience of about 6 months required for their maritime studies, but they were from different age groups. The requirement for the test subjects to have similar experience limited the number of available candidates. The experiment took 
place in an air-conditioned classroom style environment, with typical desks and cushioned chairs. The test subjects came into the room individually, at pre-booked time slots, and were guided to sit directly in front of a projector screen. A watch handover procedure was performed by the researcher with each test subject, explaining the watch keeping situation, as if they are taking over the watch. The lights were dimmed whilst the videos were played. During the experiment, only the researcher and test subject were present in the room.

Twelve people took part in this experiment, which was carried out in June 2015. Half of the test subjects received basic training, while the other half did not receive it. The aim here was to highlight the influence of appropriate training on the responses of test subjects, by training $50 \%$ of the limited number of candidates. The basic training consisted of a run through of the passage plan and a reminder of their responsibility for safe navigation. For the "Trained Group" paper charts were also provided overlaid with the route taken in the simulation videos as shown in Figure 3.

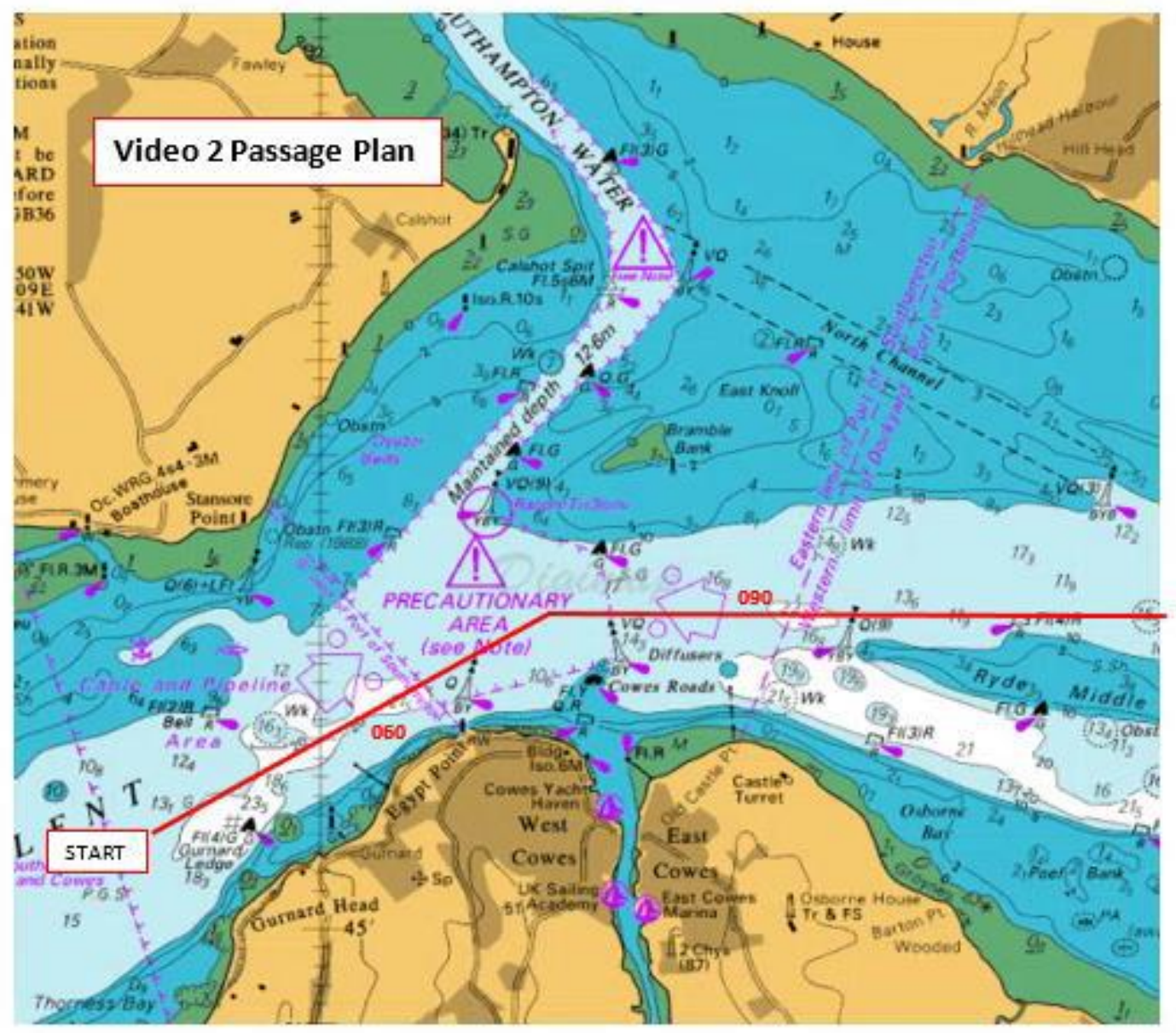

Figure 3: Overlaid passage chart

\subsection{Experiment Results}


The results from the simulation experiments were logged for analysis. They consisted of the training level, i.e. whether the test subject had received basic training, whether or not the subject recognised the failure and if so, the recognition time. In addition, results from the questionnaire were also collated in terms of automated system training, level of trust and navigation awareness course. Table 2 shows the summary of the number of people who had accurate or inaccurate situation awareness (SA) during the final simulation video. In this case, accurate situation awareness is defined as the recognition of the unexpected turn to port, whilst the course indicator showed no deviation.

Table 2: Automation Monitoring Experiment results

\begin{tabular}{|c|c|c|c|c|c|c|c|}
\hline \multirow{2}{*}{$\begin{array}{l}\text { Test } \\
\text { Subject }\end{array}$} & \multirow[t]{2}{*}{ Age } & \multicolumn{3}{|c|}{ Simulation } & \multicolumn{3}{|c|}{ Questionnaire } \\
\hline & & Training & Recognised & Recognition & Automated & Level of trust & Navigation \\
\hline & & & failure & time $(\mathrm{Sec})$ & systems & in automated & awareness \\
\hline & & & & & training & system & course \\
\hline 1 & $25-28$ & Yes & Yes & 59 & Yes & 4 & Yes \\
\hline 2 & $21-24$ & Yes & Yes & 77 & Yes & 5 & Yes \\
\hline 3 & $21-24$ & Yes & Yes & 104 & Yes & 5 & Yes \\
\hline 4 & $21-24$ & Yes & Yes & 119 & Yes & 4 & Yes \\
\hline 5 & $21-24$ & Yes & Yes & 161 & Yes & 5 & Yes \\
\hline 6 & $21-24$ & Yes & No & 180 & Yes & 5 & Yes \\
\hline 7 & $29-32$ & No & Yes & 41 & Yes & 5 & Yes \\
\hline 8 & $25-28$ & No & No & 180 & Yes & 5 & Yes \\
\hline 9 & $21-24$ & No & No & 180 & Yes & 4 & Yes \\
\hline 10 & $25-28$ & No & No & 180 & Yes & 3 & Yes \\
\hline 11 & $21-24$ & No & No & 180 & Yes & 5 & Yes \\
\hline 12 & $21-24$ & No & No & 180 & Yes & 5 & Yes \\
\hline
\end{tabular}

During each experiment, observations of the behaviour of the test subjects were also made. Of particular interest, were the different approaches taken to completing the task. Some subjects were fully engaged with completing the questionnaire, while keeping an eye on the simulation video. These subjects basically failed to recognise the autopilot failure, whereas the more effective strategy was to balance disciplined watch 
keeping with the additional task requirements. When questioned after the video, the subjects who failed to identify the situation felt that the vessel was operating normally in the final voyage. The observations made in this experiment revealed that performing two concurrent tasks, watch keeping and completing the questionnaire, could lead to ineffective situation awareness.

\subsection{Data Analysis}

For ease of analysis, recognition time was recorded as 180 seconds for those who failed to identify the unexpected autopilot behaviour. According to the data in Table 2, 50\% of the test subjects didn't recognise the failure, indicating inaccurate situation awareness. The results show that of those trained, 5 out of 6 , recognised the failure (83\%) whereas without training, 5 out of 6 test subjects (again $83 \%$ ) failed to recognise it. This emphasises the importance of training for situation awareness and safety. Interestingly the test subject with the lowest recognition time (41 seconds), meaning the most effective situation awareness, didn’t receive training.

When time to recognise that the autopilot has failed is compared with the level of trust placed in automation, there is no definite correlation, as the test subject with the lowest trust did not recognise the failure. In contrast, the shortest recognition time was by a test subject who had the highest level of trust. However, the result shows that there is a tendency towards having high trust in the automation.

Following the age band of the test subjects, Table 2 shows that there were mixed results for the 21 to 24 year olds, and the 25 to 28 year olds. Of particular interest, when recognition times of those subjects who identified failure were plotted against their age group, as shown in Figure 4, it was revealed that the most mature and experienced person, the one subject in the 29 to 32 age group, had the fastest response in recognising the failure. However, a larger number of test subjects is required before any conclusions may be drawn from this. It is the intention of the authors to conduct the larger scale study following the successful outcome of this pilot investigation. 


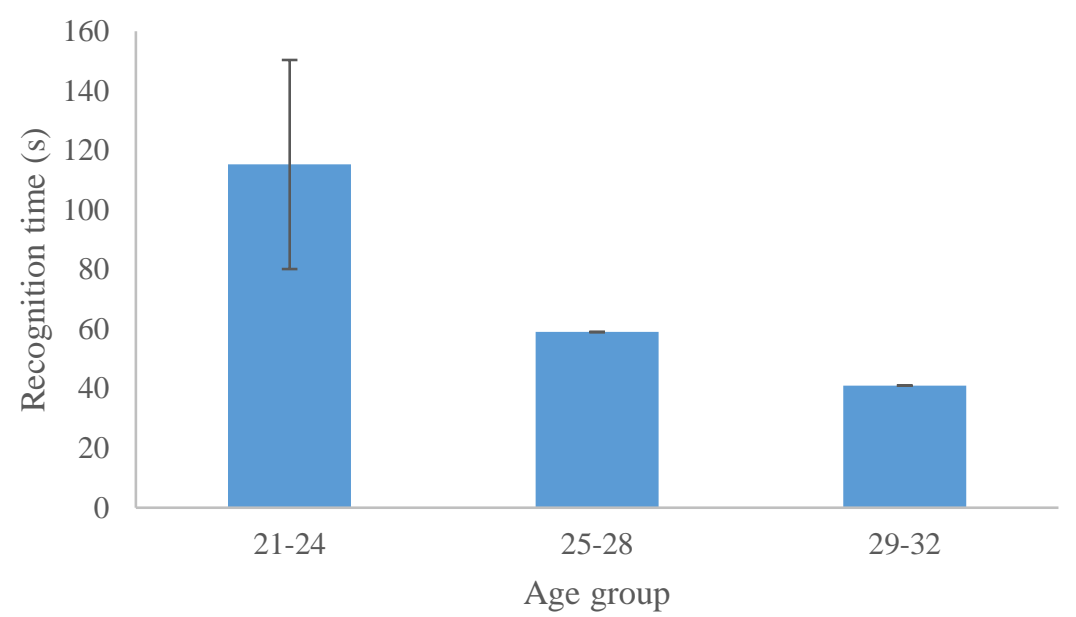

Figure 4: Recognition time against age group of test subjects identified failure

\section{Discussion}

\subsection{Automation Limitations and Experiences}

In parallel to conducting this small scale experiment, some case studies from major aviation accidents that have strong links to automation shortcomings, were reviewed and key findings and learning outcomes were identified. In this review, there were examples of complex interactions between technical and human performance weaknesses, which led to a situation from which recovery was not possible. Automation limitations such as poor situation awareness, delegated authority and ineffective monitoring were identified in the aviation accident cases reviewed (NTSB, 2014).

In the small scale experiment, the level of automation failure recognition was considered as poor. Half of the test subjects failed to effectively monitor the vessel's progress under the autopilot, and when questioned had incorrect situation awareness.

After the earlier videos, where the automated systems function normally, a level of trust was established. Therefore, a degree of complacency may have been present. This complacency may explain why, for some test subjects, the questionnaire was of much greater interest. A mentality of 'the autopilot has the vessel, I can complete the other activity' may have been experienced.

The course indicator remaining around the initial course steered by the autopilot could have also led to automation bias. A quick glance back at the screen would confirm the course was unchanged, before 
returning to complete the questionnaire. Greater weight was attributed to the information provided electronically and therefore the subtle turn of the vessel, and associated visual clues, went unnoticed.

\subsection{Improving Automation Monitoring}

From the aviation case studies considered in Section 1, a common strategy currently being employed in the industry is to remind airline pilots of their ultimate responsibility for the safe operation of their aircraft (Jarvis et al., 2014). The aim is to encourage active monitoring and improve the individual pilot's mental models of the situation.

Deck officers and masters are operating complex machines in a challenging and dynamic environment. Once underway, there may be many days of low workload and low stimulation, as the officers monitor the vessel's progress under very reliable autopilot control, with minimal opportunities to use manual skills. There are similarities to the working conditions of an airline pilot, and so the strategy of active monitoring was considered as potentially useful in maritime operations. The experiment provided an opportunity to test out the strategy, and the results were promising. Test subjects were split into two groups, with one set provided with coaching along the lines of the guidance issued in the aviation industry. Test subjects were provided with a passage plan to build a mental model of the voyage and reminded of their ultimate responsibility for safe vessel navigation.

It should be noted that the study population was diverse from ethnicity and gender perspectives, however, this pilot study had a small sample size and hence no tangible outcome measures with regard to ethnicity and gender could be drawn. The experiment, nevertheless, showed that the more consistently good performance was from the trained group. It is possible that the passage plan improved the subject's mental model of the planned voyage, and the reminder of responsibilities kept test subjects engaged with the most important task of all, safe navigation. However, the hypothesis of improved performance due to training cannot be conclusive until a higher number of experiments is conducted.

\subsection{Technical Improvements and Training}

Over the past thirty years, design methods associated with automation systems have remained unchanged (Schröder-Hinrichs et al., 2013). Confusing automation logic results in a mental model that is inaccurate. 
Results from the experiment suggest that accurate mental models are key to recognising automation failure.

Going forward, the emphasis on automation design should be on creating an effective partnership between the human and the machine (Geiselman et al., 2013). Systems should have sufficient resilience, such that no single-point failure can lead to a critical event (Hsieh et al., 2010). This may be through equipment design and redundancy, or through hardware and software barriers.

In aviation, Harry Nelson, Executive Operational Advisor at Airbus, recently stated that training should move towards building resilience so that emergencies can be tackled confidently and new safety approaches shared (Pasztor, 2015). Bainbridge suggested solution for effective monitoring especially in case of complex modes of operation is updating manual skills of operator by allowing them to practice on regular basis including training by simulator. It was also suggested that any simulators used for training should also be similarly dynamic (Bainbridge, 1983). This could be implemented in a maritime context using bridge simulators for training operators (deck officers in this case) where their manual skills be improved and provided with the appropriate information by technology in a timely manner.

The strategy for improving situation awareness, as trialled in the experiment, will require resources for implementation. As the technique is simple, this should not be a major undertaking and could be communicated with an operational circular. Training could be delivered by masters coaching their officers, or could be incorporated into bridge resource management courses.

\section{Conclusions}

This research aimed to improve understanding of automation limitations, as well as identify and evaluate current industry trends and efforts to improve the human-automation partnership. To achieve this, an extensive study was conducted, utilising a variety of data collection streams.

The review of recent aviation accidents highlighted the influence of automation on human performance, with limitations such as automation complacency. Focusing on ineffective automation monitoring and the associated degradation of situation awareness, the experiment found half of test subjects did not recognise subtle automation failure, although it should be noted that these preliminary results are from the very small number of appropriate test subjects who were available. The study showed the positive relationship between 
level of trust and perceived accuracy of situation awareness enabled by bridge technology. A strategy to

improve situation awareness showed promise in the small scale experiment conducted.

\section{References}

Bainbridge, L. (1983). Ironies of automation. Automatica, 19, 775-780.

Balfe, N., Sharples, S. and Wilson, J.R. (2015) 'Impact of automation: Measurement of performance, workload and behaviour in a complex control environment', Appl Ergon, 47, pp. 52-64.

Belev, B.C. (2004) 'Information Capabilities of Integrated Bridge Systems', Journal of Navigation, 57(1), pp. 145-151.

CAA (2013) CAP 1036 Global Fatal Accident Review 2002 to 2011. UK. [Online]. Available at: http://www.caa.co.uk/docs/33/CAP\%201036\%20Global\%20Fatal\%20Accident\%20Review\%2020 02\%20to\%202011.pdf.

Carr, N. (2015) The Glass Cage - Where Automation is Taking Us. Great Britain: The Bodley Head. Craig, C. (2012) 'Improving flight condition situational awareness through Human Centered Design', Work, 41 Suppl 1, pp. 4523-31.

Department for Transport (2014) Seafarer Statistics: 2013. UK. [Online]. Available at: https://www.gov.uk/government/statistics/seafarer-statistics-2013 (Accessed: 22 January 2015).

Dhami, H. and Grabowski, M. (2011) 'Technology impacts on safety and decision making over time in marine transportation', Proceedings of the Institution of Mechanical Engineers, Part O: Journal of Risk and Reliability, 225(3), pp. 269-292.

Endsley, M.R. (1995) 'Toward a Theory of Situation Awareness in Dynamic Systems', Human Factors, 37(1), pp. 32-64.

Endsley, M.R. (2012) Designing for Situation Awareness. USA: CRC Press.

FAA (1990) The National Plan for Aviation Human Factors. USA: Authority, F.A.

FAA (2013) Report On the Operational Use of Flight Path Management Systems. USA: (Accessed: 22nd January 2015).

Geiselman, E.E., Johnson, C.M. and Buck, D.R. (2013) 'Flight Deck Automation: Invaluable Collaborator or Insidious Enabler?', Ergonomics in Design: The Quarterly of Human Factors Applications, pp. 22-26.

Guastello, S.J. (2006) Human Factors Engineering and Ergonomics - A Systems Approach. Reprinted 2009 edn. Lawrence Erlbaum Associates Inc.

Hadnett, E. (2008) 'A Bridge Too Far?', Journal of Navigation, 61(02).

Harris, D. (2011) Human Performance on the Flight Deck. Ashgate Publishing Ltd.

Hetherington, C., Flin, R. and Mearns, K. (2006) 'Safety in shipping: The human element', Journal of Safety Research, 37, pp. 401-411

Hollnagel, E., Leonhardt, J., Licu, T., Shorrock, S., (2013) 'From Safety-I to Safety-II: A White paper', European Organisation for the Safety of Air Navigation (EUROCONTROL)

Hsieh, H.-C., Leu, J.-S. and Shih, W.-K. (2010) 'A fault-tolerant scheme for an autonomous local wireless sensor network', Computer Standards \& Interfaces, 32(4), pp. 215-221.

Jarvis, S., Shaw, P., Bagshaw, M., Cantan, C. and Skelton, S. (2014) CAP 737: Flight-crew Human Factors Handbook. Civil Aviation Authority(Accessed: 30th November 2014).

Lee, J.D. and See, K.A. (2004) 'Trust in Automation: Designing for Appropriate Reliance', Human Factors, 46(1), pp. 50-80.

Lee, J.G. and Moray, N. (1994) 'Trust, self-confidence, and operator's adaption to automation', International Journal of Human-Computer Studies, 40, pp. 153-184.

Linna, E. (2005) 'Performance of the Total Bridge Systems', Human Factors in Ship Design, Safety and Operation. London, UK, 23rd - 24th February 2005. The Royal Institution Of Naval Architects.

Lützhöft, M.H. and Dekker, S.W.A. (2002) 'On Your Watch: Automation on the Bridge', Journal of Navigation, 55(01).

Meister, D. (1999) The History of Human Factors and Ergonomics. USA: Lawrence Erlbaum Associates Inc.

Mills, S. (2006) 'Integrated Marine Electronic Systems - Some User Associated Issues for the Designer', Journal of Navigation, 59(03). 
Mosier, K.L., Fischer, U., Morrow, D., Feigh, K.M., Durso, F.T., Sullivan, K. and Pop, V. (2013) 'Automation, Task, and Context Features: Impacts on Pilots' Judgments of Human-Automation Interaction', Journal of Cognitive Engineering and Decision Making, 7(4), pp. 377-399.

NTSB (2014) Descent Below Visual Glidepath and Impact With Seawall, Asiana Airlines Flight 214, Boeing 777-200ER, HL7742, San Francisco, California, July 6, 2013. Washington DC, USA.

O'Connor, P., O'Dea, A., Flin, R. and Belton, S. (2008) 'Identifying the team skills required by nuclear power plant operations personnel', International Journal of Industrial Ergonomics, 38(1112), pp. 1028-1037.

Onnasch, L. (2015) 'Crossing the boundaries of automation-Function allocation and reliability', International Journal of Human-Computer Studies, 76, pp. 12-21.

Onnasch, L., Wickens, C.D., Li, H. and Manzey, D. (2014) 'Human Performance Consequences of Stages and Levels of Automation: An Integrated Meta-Analysis', Human Factors, 56(3), pp. 476488.

Parasuraman, R. and Manzey, D.H. (2010) 'Complacency and Bias in Human Use of Automation: An Attentional Integration', Human Factors: The Journal of the Human Factors and Ergonomics Society, 52(3), pp. 381-410.

Parasuraman, R. and Riley, V. (1997) 'Humans and Automation: Use, Misuse, Disuse and Abuse', Human Factors, 39(2), pp. 230-253.

Park, J. (2011) 'Scrutinizing inter-relations between performance influencing factors and the performance of human operators pertaining to the emergency tasks of nuclear power plant - An explanatory study', Annals of Nuclear Energy, 38(11), pp. 2521-2532.

Pasztor, A. (2015) 'Airbus Official Urges Major Pilot Training Changes', Wall Street Journaledn), 12th April 2015.

Perrow, C. (1984) Normal Accidents: Living with High-Risk Technologies. New York: Basic Books. Re, A. and Macchi, L. (2010) 'From cognitive reliability to competence? An evolving approach to human factors and safety', Cognition, Technology \& Work, 12(2), pp. 79-85.

Reason, J.T. (1990) Human Error. Cambridge England.

Sarter, N. (2008) 'Investigating Mode Errors on Automated Flight Decks: Illustrating the ProblemDriven, Cumulative, and Interdisciplinary Nature of Human Factors Research', Human Factors: The Journal of the Human Factors and Ergonomics Society, 50(3), pp. 506-510.

Schager, B. (2007) 'When Technology Leads Us Astray: A Broadened View of Human Error', Journal of Navigation, 61(01).

Schröder-Hinrichs, J.-U., Hollnagel, E., Baldauf, M., Hofmann, S. and Kataria, A. (2013) 'Maritime human factors and IMO policy', Maritime Policy \& Management, 40(3), pp. 243-260.

SEAHORSE project (2016), Safety Enhancements in transport by Achieving Human Orientated Resilient Shipping Environment http://www.seahorseproject.eu/

Sneddon, A., Mearns, K. and Flin, R. (2013) 'Stress, fatigue, situation awareness and safety in offshore drilling crews', Safety Science, 56, pp. 80-88.

Sperry Marine (2014) 'Integrated Bridge Systems', [Online]. Available at: http://www.sperrymarine.com/integrated-bridge-system/reliability (Accessed: 7th December 2014). Squire, D. (2009) 'Keeping the Human Element In Mind', Human Factors in Ship Design and Operation. London, UK, 25 - 26 February 2009. The Royal Institution of Naval Architects, pp. 1-7. SURPASS Project, (2012), Short Course Programme in Automated Systems in Shipping www.surpass.pro

Turan, O., Kurt, R. E., Arslan, V., Silvagni, S., Ducci, M., Liston, P., Schraagen, J. M., Fang, I., Papadakis, G. (2016) 'Can we learn from aviation: safety enhancements in transport by achieving human oriented resilient shipping environment', Transport Research Procedia 14, pp. 1669-1678 VSTEP (2008) 'Ship Simulator 2008'. The Netherlands: VSTEP BV.

Wickens, C.D. and Hollands, J.G. (2000) Engineering Psychology and Human Performance. Third Edition edn. USA: Prentice-Hall Inc.

Wiener, E.L. (1989) Human Factors of Advanced Technology Transport Aircraft. USA: Administration, N.A.a.S. [Online]. Available at: http://humanfactors.arc.nasa.gov/publications/HF_AdvTech_Aircraft.pdf.

Wiener, E.L. and Curry, R.E. (1980) 'Flight-Deck Automation: Promises and Problems', Ergonomics, 23(10), pp. 995-1011. 